\title{
A Computer Simulated Model for Load-Application Capacity Check of Chicken Egg
}

\author{
Hasan Dehghanzadeh Najm Abad ${ }^{1,}$, , Eisa Salajegheh ${ }^{2}$, Amir Ahmad Hedayat $^{1}$ \\ ${ }^{1}$ Department of Civil Engineering, Azad University, Kerman, Iran \\ ${ }^{2}$ Department of Civil Engineering, Bahonar University, Kerman, Iran
}

Email address:

hassan.dehghanzadeh@yahoo.com (H. D. N. Abad), eysasala@mail.uk.ac.ir (E. Salajegheh), amirahmad1356@yahoo.com (A. A. Hedayat)

\section{To cite this article:}

Hasan Dehghanzadeh Najm Abad, Eisa Salajegheh, Amir Ahmad Hedayat. A Computer Simulated Model for Load-Application Capacity Check of Chicken Egg. American Journal of Civil Engineering. Special Issue: Research and Practices of Civil Engineering in Developing Countries. Vol. 3, No. 2-2, 2015, pp. 44-52. doi: 10.11648/j.ajce.s.2015030202.19

\begin{abstract}
The material, form and geometric shape of egghavebeen designed in a way that nobody could ever break an egg squeezing it lengthwise. This research is based on the pattern of human palm. Two soft and concave seating bases are built in order to hold the two ends of the chicken egg. Differentchicken eggs with various geometric shapes were examined by Zwick compression strength test while they were raw, baked and empty. The maximum failing force (breaking of the egg) was 988 Newton.Static linear and nonlinear analysis and modeling of material and geometry is done by Ansys software or with Shell181 element. Early results show that chicken egg content has no effect on its load-application capacity and the reason of breaking are exceeded orbital tensile stresses. With the same thickness, eggs with length to width ratio of 1.4 have the highest load-application capacity and eggs with length to width ratio of 1.7 have the lowest load-application capacity.
\end{abstract}

Keywords: Chicken Egg, Geometric Properties, Axial Compression Strength, Linear and Nonlinear Static Analysis of Geometry and Material

\section{Introduction}

Chicken egg is a wonderful thing created by God which has a beautiful geometry and advanced engineered structure. With full safety and nutritional features, this structure is an appropriate place for the growth of a being. This structure has a protected outer shell (cuticle) made of lime with microscopic pores which allow carbon dioxide exchange with outside and let air into the shell. Under the chicken egg shell there are two transparent protein membranes which have defensive role against bacterial invasion. The combination of membranes and calcareous shell forms a composite structure which is the main load-bearing structure. In Figure1 the transparent protein membrane (made of human hair) and in Figure2 the Mammillary sponge layer (or knob) is shown. Hard calcite crystals are made over Mammillary knobs and these layers (or knobs)act as composites. Indeed, the transparent membrane is like a paper that is tensile resistant but has a weak performance under compression. So, in the composite element the protein membrane is utilized as the tensile resistant member and the hard calcite layer is utilized as compressive resistant member. Meanwhile, in longitudinal load application of the two ends of the chicken egg, in meridional direction we have compressive forces an in orbital direction we have both compressive and tensile forces.

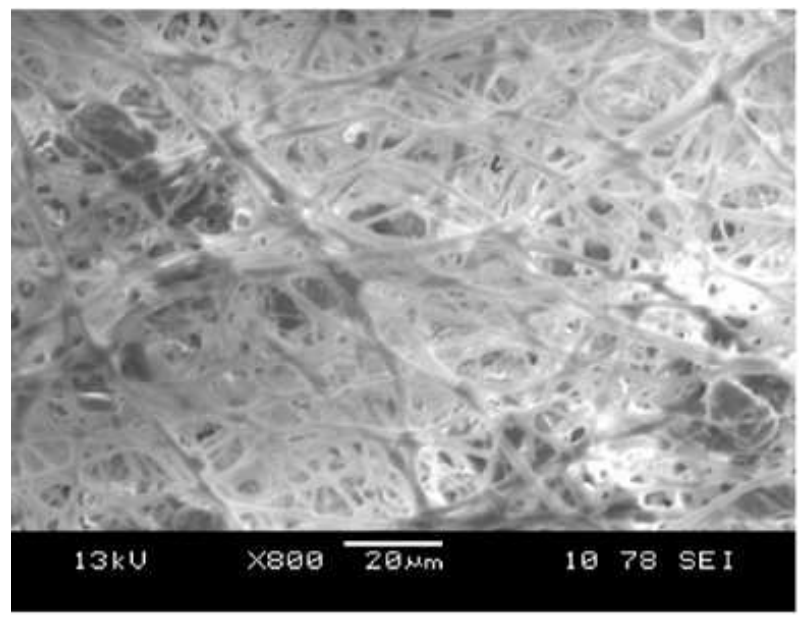

Figure 1. Transparent protein membrane [2] 


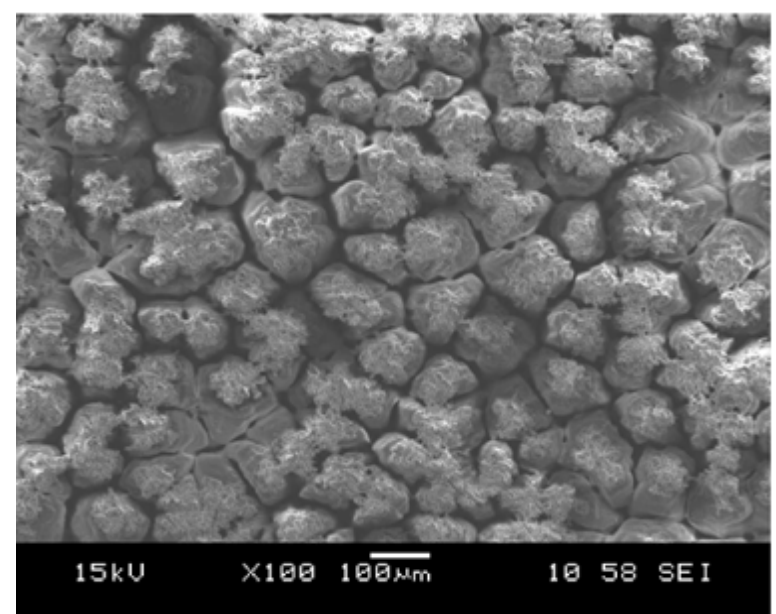

Figure 2. Mammillary sponge layer [2]

The main food sources of the embryo in the chicken egg are yolk and albumen which are stored for 21 days. The air cell and Chalaza bands are other parts of this structure. The air cell provides oxygen and the Chalaza bands suspend the yolk in the center of the albumen. This research deals with geometric structure, structural materials and its load-bearing capacity. This research has nothing to do with the formation of the environmental, chemical properties and effective factors on these qualities. This work style was used in our previous research in ValiAsr University of Rafsanjan and was done by triaxial compression test and maximum failure load (breaking of the egg) of 750 Newton was measured. The experimental results were analyzed by Ansys linear static analysis. In this research, in order to achieve better results, the Zwick strength testing machine was used which belonged to Kerman University. Meanwhile, the results were analyzed by Ansys nonlinear static analysis.

Shell structures are one of the greatest structures because they transmit forces in numerous directions. Many natural forms are made of shells. Water and gas containers, silos, bow-shaped dams, fuselage, ship and automobile bodies are examples of shell structures. In the past because of the lack of tensile-resistant materials, brick and clay were used for construction of shell structures such as domes and arched vaults.Due to its non-expandable geometry, the egg shell has high mechanical and load-bearing capacity. This structure is symmetrical in its longitudinal axis but is asymmetric in its transversal axis. So, this structure has a narrow tip and a flat bottom.

\section{Description of the Work}

First, some samples of chicken egg are provided and tested longitudinally by the machine. The loading is done incrementally on a small area of the narrow tip and the flat bottom is placed on the seating base. The maximum failure load is measured for every sample. Then samples are modeled in Ansys software. The maximum load is applied and through an experimental method all stresses and reasons of failure (breaking) in this structure are analyzed. In the research of Periann and his colleagues [2] and P. Coucke and his colleagues [3], a nondestructive method was used. In the research of Ashley Lloyd and his colleagues [4] the samples were placed between two flat metal plates. In this research all samples are located in soft and flexible seating bases that are in compliance with the two ends of an egg. In this way, the transmitted load is applied superficially to both narrow tip and flat bottom of eggs. The load-application rate is $0.5 \mathrm{~mm}$ per minute. In this research the load-application rate is not adapted to Ahmeds [5]. Nedomova [6], Ketelare [7], Voisey [8] and Buchar [9] research studies.

We provided 20 raw eggs, 20 baked eggs and 20 empty eggs. For each part a variety of white, colored, round, oval, small and big chicken eggs are selected. We baked eggs for 20 minutes in boiled water. The cracked eggs are omitted. By a syringe needle we emptied eggs through a small hole in the top of the egg. After this the hole is filled by adhesive.

For this experiment we used Zwick strength testing machine in Bahonar University of Kerman (Fig.3). This machine was manufactured in Germany and is used for loadapplication of a wide range of materials. This machine is controlled by an attached computer and has special options for customizing sample dimensions, load-application rate etc. the outputs are in the format of excel and diagrams.

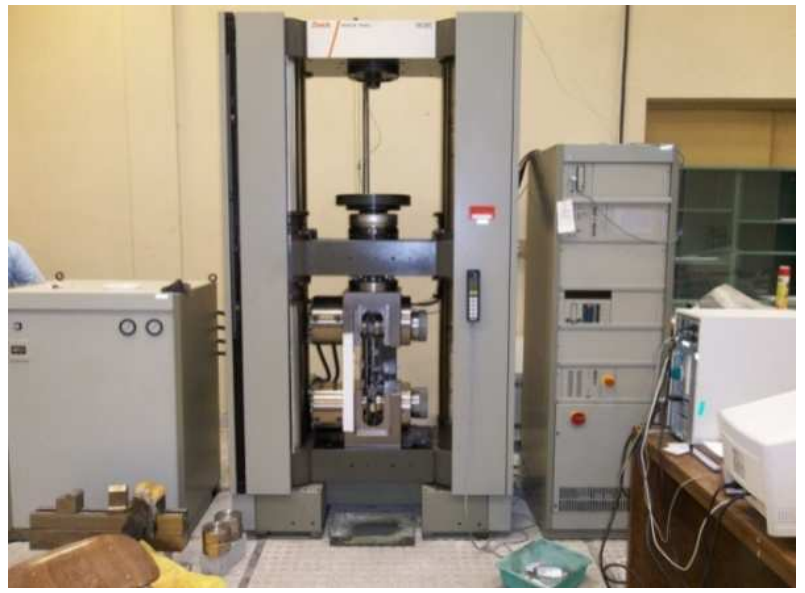

Figure 3. Zwick testing machine

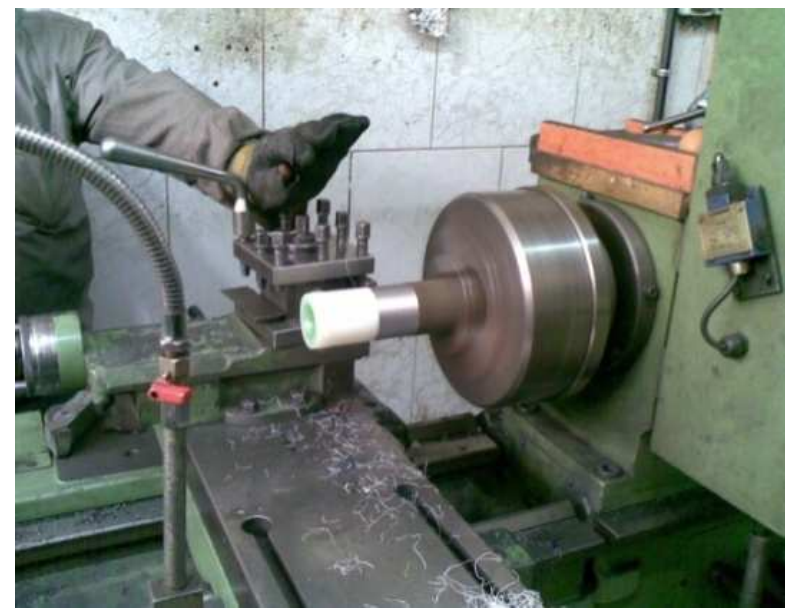

Figure 4. Turning for creating a seating base 
In this research the load application is done widely on a small area of the narrow tip and a small area of the egg bottom is considered as its seating base. So, we need deep and flexible seating bases to be installed on two sides of a metal shaft then we connect shafts to the machine. The seating base is made of compressed Teflon cylindrical tube with $10 \mathrm{~cm}$ diameter and $15 \mathrm{~cm}$ of height (Fig.4 and Fig.5). In a casting workshop we used the biggest egg and sand to provide a metal plate with $5 \mathrm{~mm}$ thickness and in turning workshop we cut the quadrant of its two ends to provide a device to deepen the Teflon cylinder. According to main sample, the depths of these bases are all $11 \mathrm{~mm}$. Then these cylinders were installed on metal shafts with $10 \mathrm{~cm}$ diameter and $20 \mathrm{~cm}$ of height.

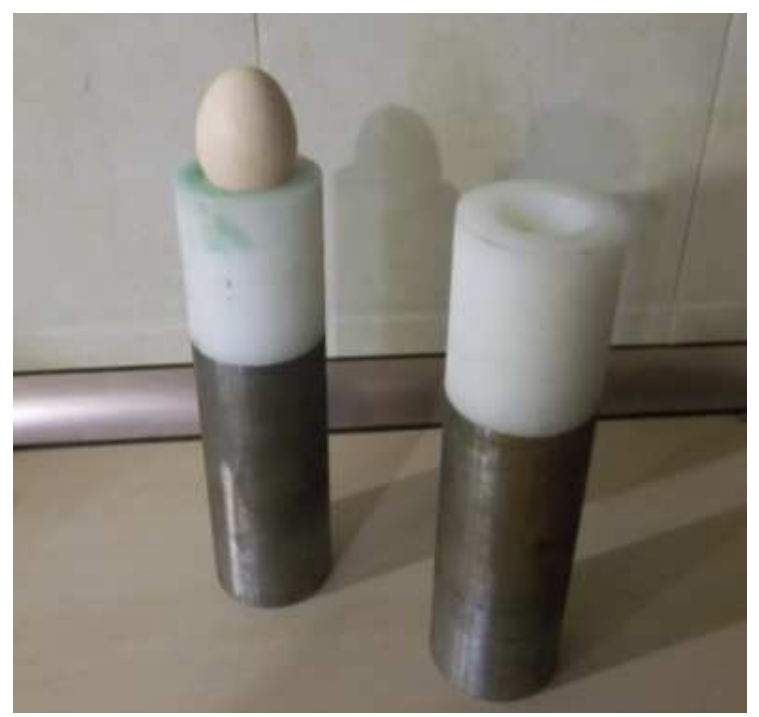

Figure 5. Seating base

\section{Testing}

Geometric properties such as length, width and shell thickness (after breaking of the egg shell) of all samples are measured precisely and then are placed in testing machine. After necessary settings, the machine starts to apply the load and the results are recorded. Many of samples broke early after the load-application because of various reasons such as slipping from the seating base, existence of cracks or other weak points that were not visible by eye, or low strength of the shell. These samples were not considered in calculations. To make the seating base a big egg was used so the base was loose for some samples. In this case we used foam sheets to fix the egg in the seating base (Fig.6). Recorded strains are caused by compression of the foam, Teflon and samples so they are not reliable for the egg structure.

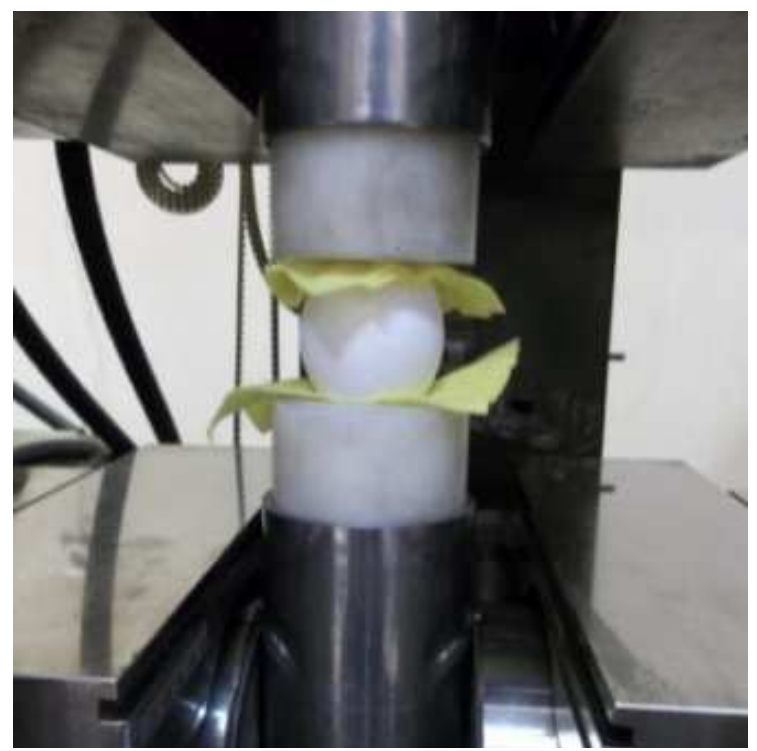

Figure 6. Placement of the sample inside the machine

In this regard ten samples were chosen among different types of eggs which their geometric properties are mentioned in Table2. The highest load-bearing capacity is for rows number 1 and 2 . In these samples the length to width ratio is 1.42 and 1.41. Also, the lowest load-bearing capacity is for row numbers 7 and 9. In these samples, with equal thickness, the length to width ratio is 1.7 and 1.68. Tthe results show that eggs with more natural and more spherical shapes are more resistant (an approval for Jacobs and his colleagues [10] and Narushin and his colleagues [11], research). In other words, longer eggs have les resistance. This matter approves Ebubekir Altuntas research [12] (in Abubekir research, SI (shape index) is width to length ratio). Meanwhile, the highest resistance occurs in the highest width (Anderson and et al.[13]).

Table 1. Geometric properties of samples

\begin{tabular}{|c|c|c|c|c|c|c|c|c|c|}
\hline NO & Contents & Fac. / Home & Color & Length & Width & Thickness & Weight & Press & $\mathbf{L} / \mathbf{W i}$ \\
\hline 1 & Empty & Home & Brown & 55.4 & 39 & 0.35 & 61 & 988 & 1.42 \\
\hline 2 & Raw & Home & Brown & 60 & 42.5 & 0.35 & 58 & 878 & 1.41 \\
\hline 3 & Empty & Factory & White & 60 & 41 & 0.38 & 61 & 787 & 1.46 \\
\hline 4 & Raw & Home & Brown & 56 & 35.5 & 0.36 & 59 & 576 & 1.58 \\
\hline 5 & cooked & Factory & White & 54.5 & 33 & 0.35 & 57 & 365 & 1.65 \\
\hline 6 & Raw & Factory & White & 53.5 & 33 & 0.35 & 60 & 364 & 1.62 \\
\hline 7 & Raw & Home & Brown & 54.5 & 32 & 0.35 & 61 & 326 & 1.70 \\
\hline 9 & cooked & Home & Brown & 60.5 & 36 & 0.35 & 57 & 163 & 1.68 \\
\hline 10 & Empty & Factory & White & 57 & 35.5 & 0.34 & 59 & 110 & 1.61 \\
\hline
\end{tabular}

The above results confirm our previous researches. The geometric properties of samples are in Table 1. 

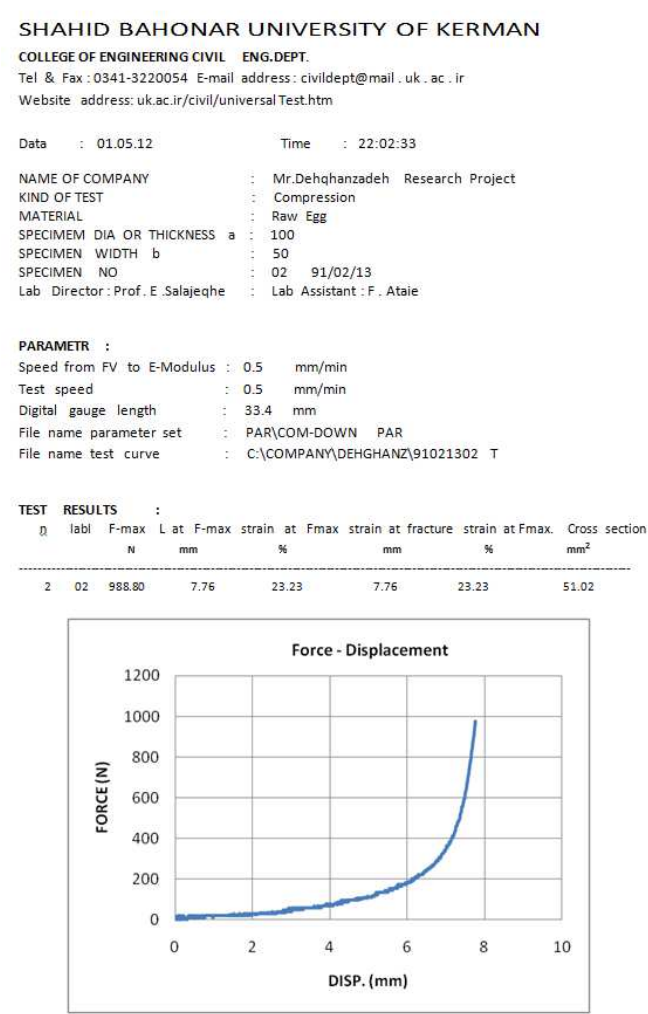

Figure 7. The diagram of force-displacement with the capacity of 576Newton

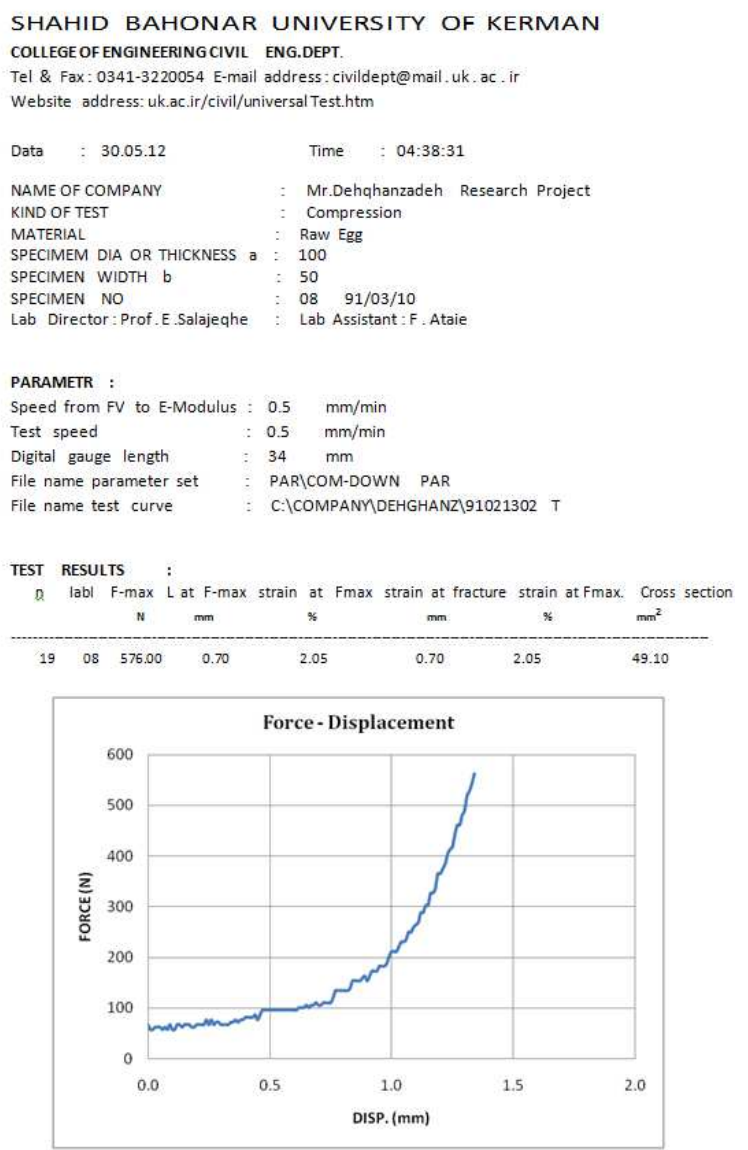

Figure 8. The diagram of force-displacement with the capacity of 988Newton
The outputs from test results of rows number 1 and 4 are illustrated in Figure 7 and Figure 8 The great displacement is caused by usage of foam and its compression. The aim of this test is to determine the load-bearing capacity of the chicken egg, so we had to put foam under the samples in order to prevent local failure and to prevent stress concentration. The strain- stress diagram of all samples have relatively uniform pattern. In calculation of stress, the extremity of the ring with lowest area was used. In this method, depending on the created seating base, the maximum applied load on a small area of the egg's narrow tip was $988 \mathrm{Newton}$. Whereas in Macleod research, regardless of the load-application method, the maximum applied load was 40 Newton, in Ashley Lloyd research this figure was 200 Newton, in De Ktelaere research this figure was 37.8 Newton, in Zlatica, Vitorovic and Lukic [14] this figure was 35.3, in Pilat [15] research this figure was 10.5 Newton and in Tung [16] research the maximum applied load was 31 Newton. In our previous research this figure was 750 Newton.

\section{Modeling of Chicken Egg in AutoCAD and Ansys Software}

For the creation of a model in Ansys environment, version 13, first we scanned a sample chicken egg which its shape was more proper and more real. Then we started to create a real model in AutoCAD. The result was saved in Sat. format and was analyzed in Ansys. The chicken egg longitudinal axis is $\mathrm{X}$ and its transversal axis is $\mathrm{Y}$.

The $\mathrm{Z}$ axis is a transversal axis, too. Based on the experimental pattern and the depth of the seating base on the two ends of the chicken egg, two areas were created as the load-application area and support area with $11 \mathrm{~mm}$ of depth. The Shell181 was used as a layer with $0.35 \mathrm{~mm}$ of thickness, without considering the impact of composite. This element is appropriate for the analysis of thick and thin Shell structures. It is a 4-noded element with 6 degrees of freedom at each node (three translational and three rotational) which is appropriate for linear analysis of great rotations and nonlinear analysis of strains.

\subsection{Elastic Modulus of Chicken Egg}

According to the Coak and colleagues research, the elastic modulus was 31000 Mega Pascal and according to Tang research, by using Reissner method [17], the elastic modulus of a chicken egg was 46000 Mega Pascal. This Figure was 55000 Mega Pascal in Meloyd research and was $30000 \mathrm{mPa}$ in Bain [18] research. In this research, the elastic modulus of a chicken egg was considered 47000 Mega Pascal and the Poisson's ratio was 0.25 .

\subsection{Various Analysis of a Chicken Egg in Ansys Software}

The properties of samples including length, width and thickness of the shell in mm, the amount of transmitted load in Mega Pascal, load-application area in square meters and the length to width ratio is based on Table1. The seating base 
depth is $11 \mathrm{~mm}$, so in Ansys, the load-application area of the two ends were considered to the depth of $11 \mathrm{~mm}$ into the model and were bounded to translation and rotation (all dofs $=0$ )

\subsection{Linear Static Analysis}

According to rows number 1, 2, 7 and 9 in Ansys Software with elastic modulus of 47000 Mega Pascal and 0.25 Poisson's ratio, we considered 10 steps of load applying. According to experimental loading, the maximum load was one thousand Newton. In this analysis all steps are loaded.
The unit of displacement is $\mathrm{mm}$ and stress unit is Mega Pascal. The Sx stress represents meridional stresses along longitudinal axis of the egg and Sy represents orbital stresses along transversal axis. The negative numbers represent compressive stress and positive figures represent tensile stress. Svon represents Von Mises stress. The center index is related to average stress in the middle of the sample. The Table 2shows the results of linear static analysis and Figure9 and Figure 10 illustrates Sy and Sx stresses in samples of row 1.

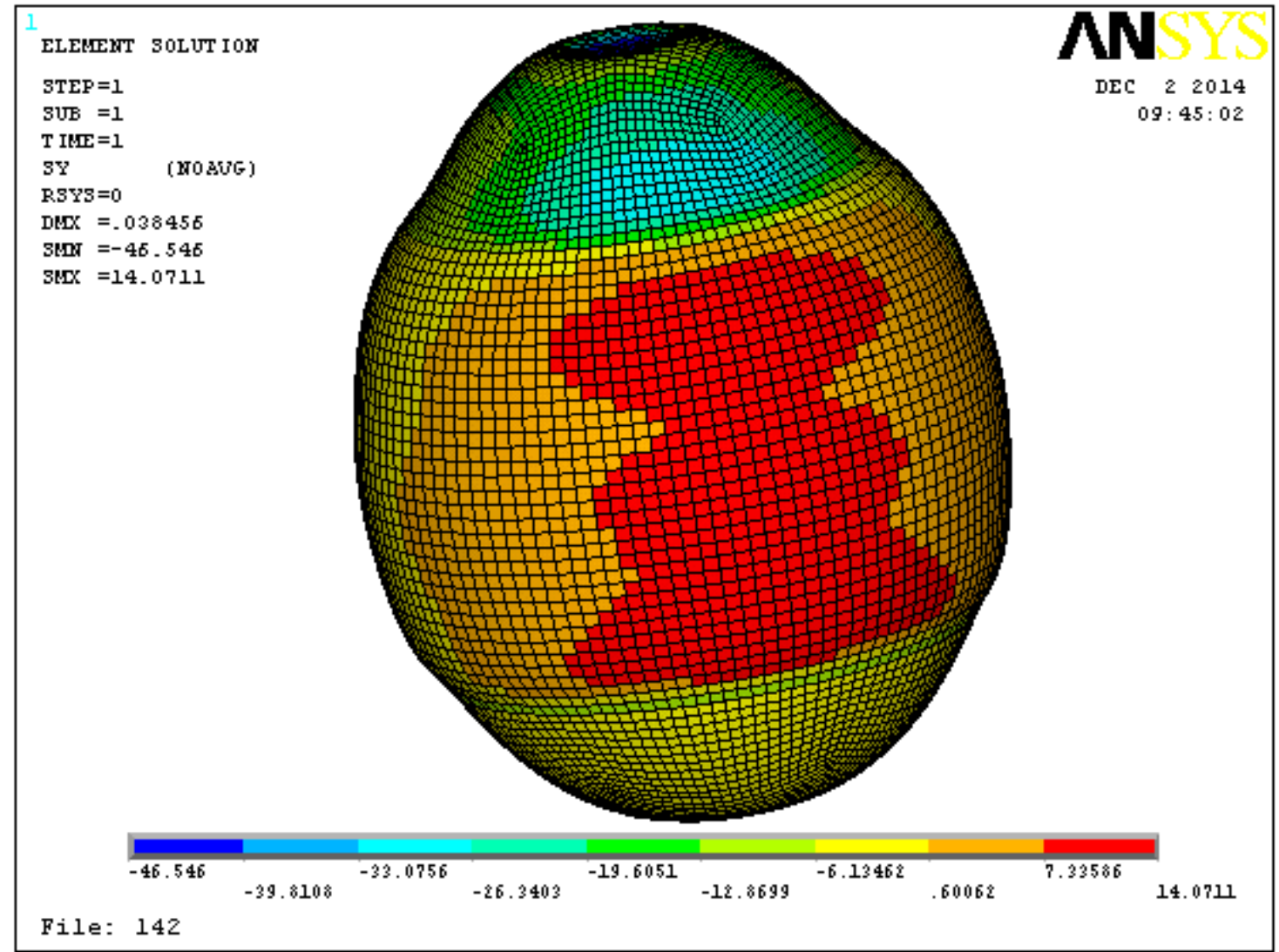

Figure 9. Sy stress for sample1

Table 2. Results of linear static analysis

\begin{tabular}{|c|c|c|c|c|c|c|c|c|c|c|c|c|c|c|c|c|c|}
\hline Analyse & No & Length & Width & Thickness & $\mathbf{L} / \mathbf{W i}$ & Press & Area & Def. & Sx)min & Sx)max & Sx)center & Sy)min & Sy)max & Sy)center & S)von & S)von0center & step \\
\hline L_S & 1 & 55.4 & 39 & 0.35 & 1.42 & 0.824 & 1213.7 & 0.038 & -33.86 & 4.76 & -14 & -46.55 & 14.071 & 10 & 45.2 & 22 & 10 \\
\hline L_S & 2 & 60 & 42.5 & 0.35 & 1.41 & 0.617 & 1621.4 & 0.1041 & -31.99 & 6.6 & -12 & -91.34 & 15.06 & 9 & 89 & 14 & 10 \\
\hline L_S & 9 & 60.5 & 36 & 0.35 & 1.68 & 0.744 & 1343.2 & 0.098 & -31.47 & 2.99 & -14 & -98.65 & 21.54 & 14 & 96.2 & 11 & 10 \\
\hline $\mathrm{L} S$ & 7 & 54.5 & 32 & 0.35 & 1.7 & 0.895 & 1116.9 & 0.06 & -32.62 & 1.39 & -15 & -80.15 & 11.28 & 6 & 78.98 & 30 & 10 \\
\hline
\end{tabular}

\subsection{Nonlinear Static Analysis of Geometry and Materials}

For Nonlinear Static Analysis of Geometry and Materials, after creating a model based on available samples, linear profile of materials including elastic modulus and Poisson's ratio are respectively $47000 \mathrm{Mega}$ Pascal and 0.25 and nonlinear profiles of materials according to relation number "(1-4-8)" are yield stress of 36 Mega Pascal and Tangent modulus of 1 Mega Pascal. For calculating the yield stress, the maximum bearing load derived from experimental results is divided by the cross section of the seating base bottom (circle perimeter* thickness).

$$
\sigma=-1000 /(3.14 * 25 * 0.35)=-36.38 \mathrm{MPa}
$$

The tangent modulus of the chicken egg is considered one because its Tangent modulus is not available and is very brittle. We considered 10 steps of load applying. According to experimental loading, the maximum load was one thousand Newton. The Table3represents nonlinear static analysis results and Figure 11 and Figure 12 represent 
Svonand Sx stresses of the samples of the row number 7 .

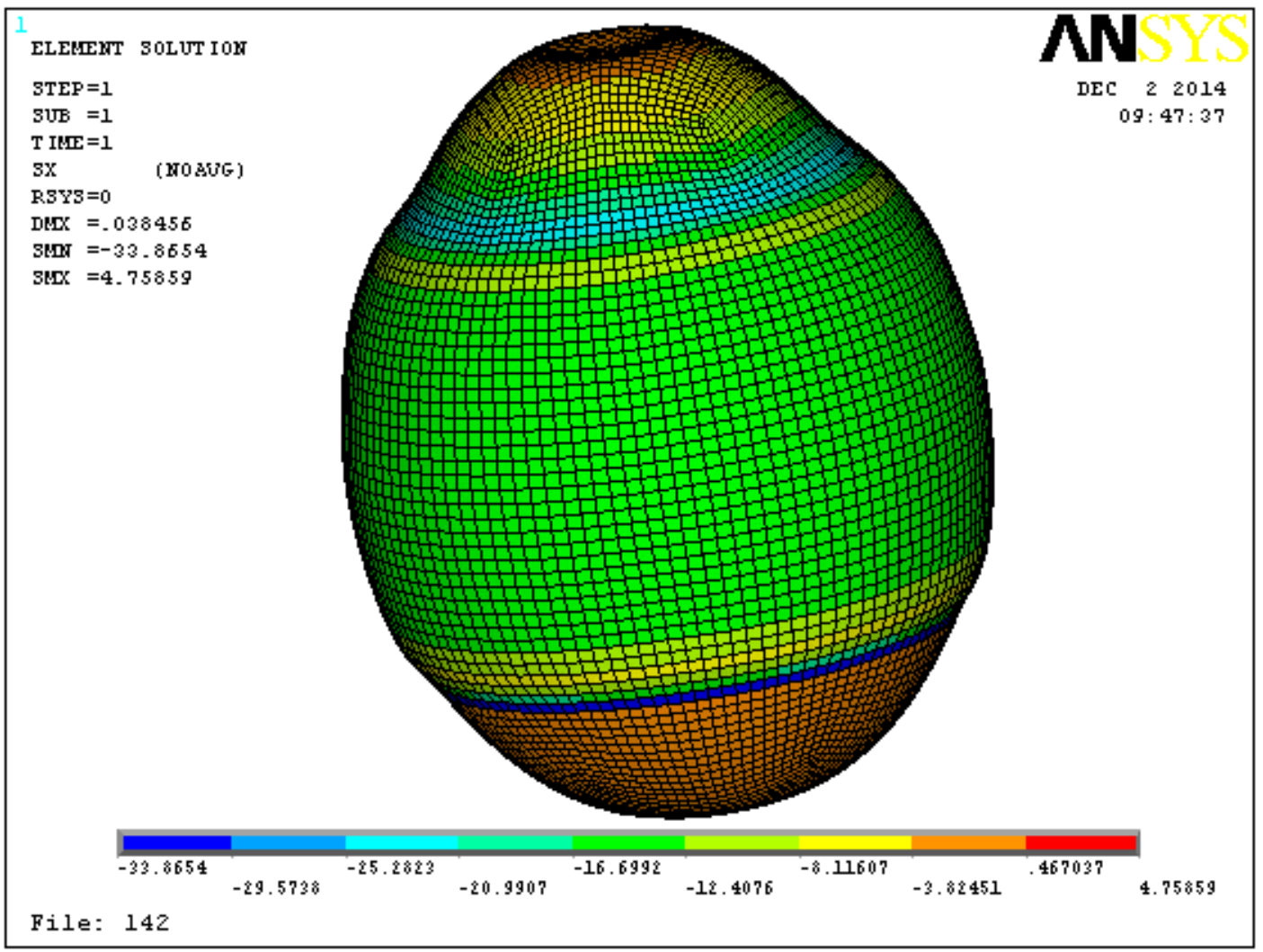

Figure 10. Sx stress for sample1

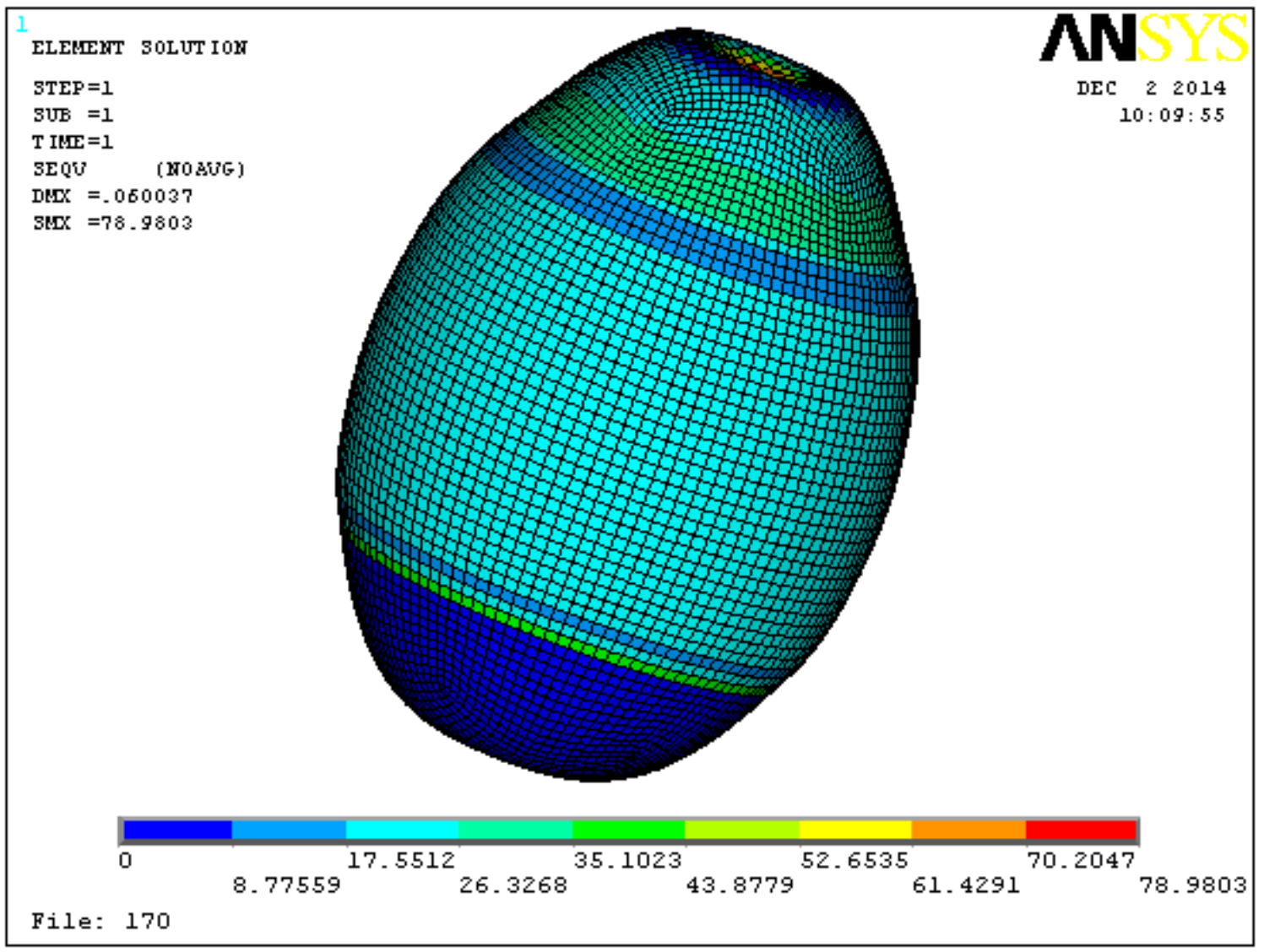

Figure 11. Svon stress for sample 7 


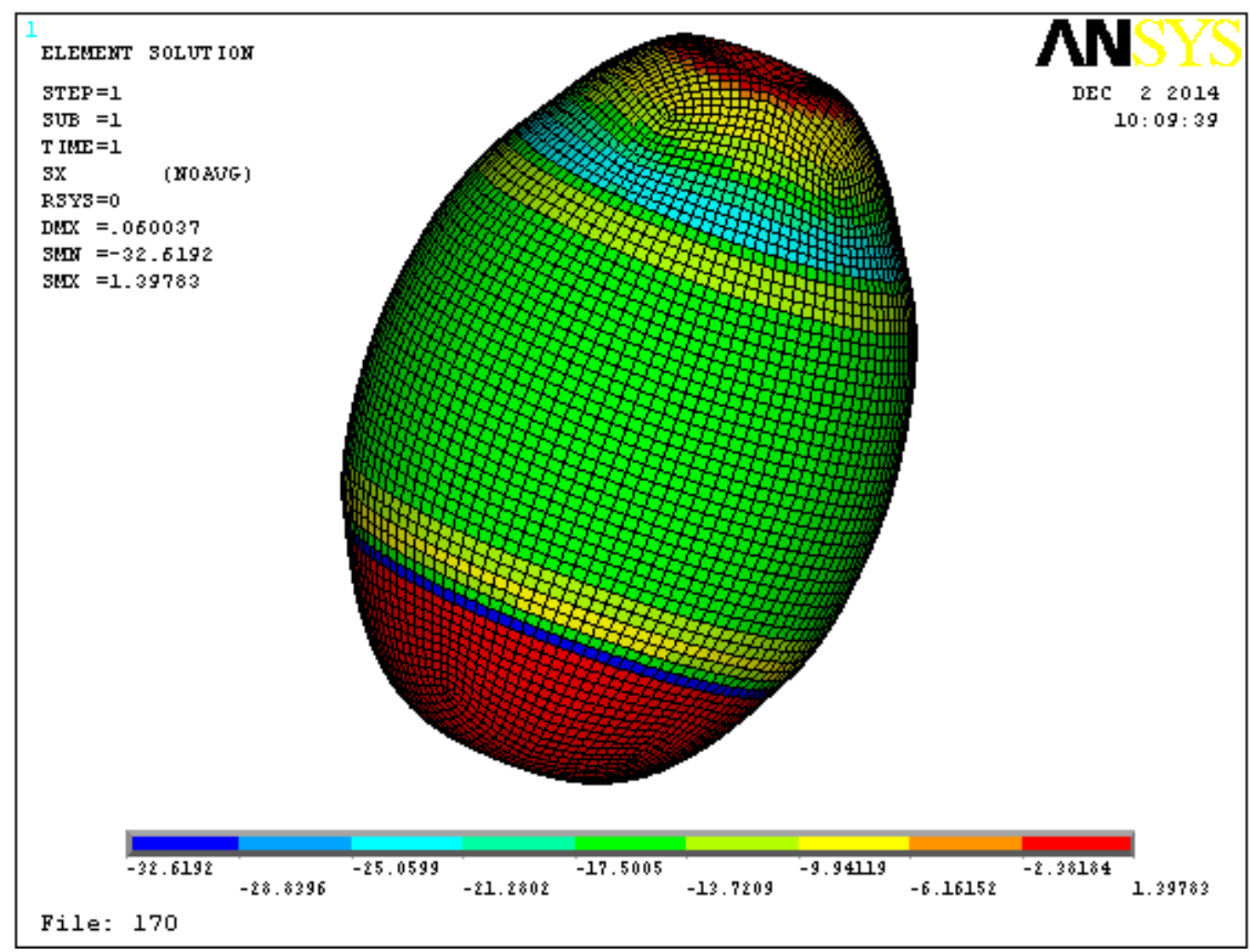

Figure 12. Sx stress for sample 7

Table 3. Nonlinear static analysis results

\begin{tabular}{|c|c|c|c|c|c|c|c|c|c|c|c|c|c|c|c|c|c|}
\hline Analyse & No & Length & Width & Thickness & $\mathbf{L} / \mathbf{W i}$ & Press & Area & Def. & Sx)min & Sx)max & Sx)center & Sy)min & Sy)max & Sy)center & S)von & S)von0center & step \\
\hline NL_S & 1 & 55.4 & 39 & 0.35 & 1.42 & 0.824 & 1213.7 & 0.041 & -30.61 & 4.99 & -12 & -38.06 & 14.37 & 11 & 36 & 20 & 10 \\
\hline NL_S & 2 & 60 & 42.5 & 0.35 & 1.41 & 0.617 & 1621.4 & 0.13 & -19.24 & 4.02 & -7 & -41.5 & 30.56 & -2 & 36 & 10 & 6 \\
\hline NL_S & 9 & 60.5 & 36 & 0.35 & 1.68 & 0.744 & 1343.2 & 0.145 & -18.94 & 2.81 & -7 & -40.45 & 41.11 & 1 & 36.02 & 10 & 6 \\
\hline NL $\mathrm{S}$ & 7 & 54.5 & 32 & 0.35 & 1.7 & 0.895 & 1116.9 & 0.066 & -26.16 & 1.65 & -12 & -40.7 & 17.43 & 13 & 36 & 10 & 8 \\
\hline
\end{tabular}

\subsection{Displacement of Load-Application Point and the Lean Area}

When changing the support area in an experimental model, the results of load application are very weak and samples fail under very small loads. So, we changed the lean and load- application location in Ansys model. We applied load on the flat tip of the egg and moved the lean area to the narrow tip. Then we realized that with 1000 Newtons of load, Sx stresses stay the same by Sy stresses sharply increase. These results are shown in Table 4and ros 22 and 99 are new models where the load and the lean location have changed.

Table 4. Results of moving the leant area in Ansys model

\begin{tabular}{|c|c|c|c|c|c|c|c|c|c|c|c|c|c|c|c|c|c|}
\hline Analyse & No & Length & Width & Thickness & $\mathbf{L} / \mathbf{W i}$ & Press & Area & Def. & Sx)min & Sx)max & Sx)center & Sy)min & Sy)max & Sy)center & S)von & S)von0center & step \\
\hline L_S & 2 & 60 & 42.5 & 0.35 & 1.4 & 0.6 & 1621.39 & 0.104 & -31.99 & 6.6 & -12 & -91.34 & 15.06 & 9 & 89 & 14 & 10 \\
\hline L_S & 22 & 60 & 42.5 & 0.35 & 1.4 & 0.5 & 1874.13 & 0.199 & -25.8 & 1.32 & -13 & -147 & 58.5 & 7 & 147 & 20 & 10 \\
\hline L_S & 9 & 60.5 & 36 & 0.35 & 1.68 & 0.74 & 1343.24 & 0.098 & -31.47 & 2.99 & -14 & -98.65 & 21.54 & 14 & 96.2 & 11 & 10 \\
\hline L S & 99 & 60.5 & 36 & 0.35 & 1.68 & 0.65 & 1538 & 0.18 & -26 & 2.45 & -13 & -155 & 67.85 & -0.4 & 155 & 20 & 10 \\
\hline
\end{tabular}

\section{Results}

Applying load from the narrow tip and placing the lean area on the flat bottom of the chicken egg cause orthogonal tensile stresses which are orbital tensile forces (Sy) of the model. Because of egg brittle calcareous shell which has low tensile resistance, the shell fails and cracks. But it can withstand compressive forces because of its two-sided vaulted shape. To prove this matter, we press a cracked sample along its longitudinal axis. As it is shown in the Figure 13, the vertical cracks are opened in an orbital pattern. In experimental samples no buckling is observed in the egg shell (no deformation). Also, in Ansys model the bending stresses are negligible and this shows that in such structures buckling is very weak. 


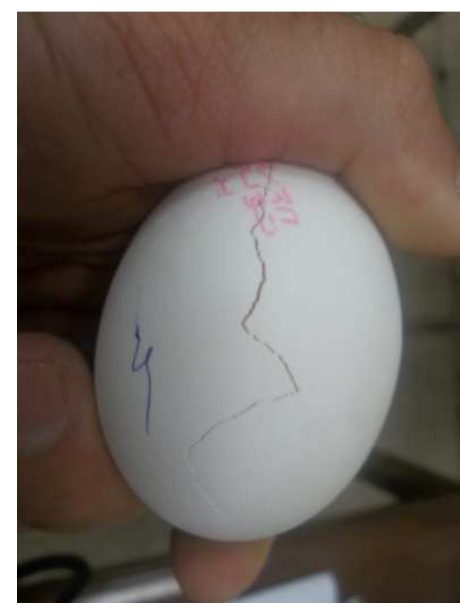

Figure 13. cracks opening

\section{Discussion and Conclusions}

The above results show that all meridional compressive stresses (Sx) are compressive, but due to stress concentration the lean areas are exceptions. But orbital stresses (Sy) are compressive in some points and in adjacent points to the lean areas stresses are tensile. These tensile stresses cause crack along the longitudinal axis of the chicken egg and breaks the egg from two sides.

The lean status changing from All Dof $=0$ to $U x, y, z=0$ has no significant effect on Ansys results. Maximum tensile stresses are formed on the flat side of the egg and are transmitted to other parts. Maximum compressive stresses of Sx and Sy are formed by concentration of stress in the lean or in load-application surfaces.

According to relation 1-4-8, if we consider -36Mega Pascal for the allowable stress, we will realize that all compressive stresses of Sx are in allowable limits and Sy stresses exceed allowable limit.

The results show that chicken egg content has no important role in load-bearing capacity and it's geometric shape of the eggshell which has the main role. In above conditions, the egg is capable of withstanding 988 Newton of load. Meanwhile, we can improve egg bearing ability by providing soft, flexible and deep seating bases for the narrow tip and flat bottom of the egg because these bases prevent brittle shell from failure (break).

The geometric form and shape of an egg have the main role in its load-bearing capacity. This form changes the load into orbital forces while there is a little amount of bending. The calcareous eggshell shows a proper behavior under compressive loads. But it has low tensile resistance and this causes tensile cracks at the highest part of the egg in contact to lean area. Creation of these cracks and longitudinal expansion of them to the other side is the reason of egg failure (break).

We use a needle to empty the egg content. If we pimp air inside the eggshell it will explode loudly. This shows that the eggshell can withstand no pressure from inside. At the end of growth period this feature lets the chicken to easily come out of the egg.
Experimental results show that in chicken eggs with the same shell thickness, eggs with length to width ratio of 1.5 have the highest load-bearing capacity and eggs with length to width ratio of 1.7 have the lowest load-bearing capacity. But in software models, maximum compressive stresses usually occur in the lean area and only the maximum orbital tensile stress occurs outside and near the lean area. For various models no same (equal) procedure was observed.

The total applied load changes into meridional and orbital forces and moments are little. The meridional forces are mostly compressive with an exception in the seating bases which are caused by stress concentration. But orbital forces are compressive in some parts and in the bottom of the lean area are tensile. These tensile forces cause orbital tensile stresses and create cracks in this part. The longitudinal expansion of these cracks causes the egg to fail (break).

The results show that if we build structures based on the shape of chicken egg we can build roofs with thin thickness and large spans. Even if we consider orbital and meridional reactions in parts of this structure, we still can build it.

If we use tensile resistant elements in an orbital or angled way in order to prevent tensile forces that cause cracks in the lean area, we can achieve higher load-bearing capacity. This shows the role of composite layers. In an eggshell, if the calcareous crystals are safely connected to the internal membranes, we will achieve higher load-bearing capacity. So, the protein membranes have two roles, a barrier for bacterial invasions and a structural role as a composite structure. The later can be studied as "The Analysis of structural resistance of a chicken egg with composite shell" in another research.

\section{References}

[1] M. Farkhooii, T. Sigaroodi and F. Niknafs," a complete guide to poultry," Iran institute of aviculture,1999.http://www.mardoman.net/?id=596\&pt=full\& $\mathrm{sn}=$ articles

[2] C. Perianu a, B. De Ketelaere a, B. Pluymers b, W. Desmet b, J. De Baerdemaeker a, E. Decuypere aa Division MeBioS, KU Leuven, Dept Biosystems, KasteelparkArenberg 30, B-3001 Heverlee, Belgium Department of Mechanical Engineering, Division PMA, KU Leuven, Celestijnenlaan 300B, B-3001 Heverlee, Belgium. biosystems engineering 106 (2010) 79e85. journal homepage: www.elsevier.com/locate/issn/15375110

[3] P. Coucke, G. Jacobs and ets, "comparative analysis of the Static and Dynamic Mechanical Eggshell Behaviour of a Chicken Egg”, In: Proceeding of international Conference on Noise and Vibration Engineering, Long Beach, CA, USA, (1998).

[4] Ashley Lloyd, Tara Vaziri, Sam Yang, "A composite of crystal inelayers and membrane proteins: A mechanical, structural, and compositional investigation of eggshells", April 18, 2011.

[5] Ahmed, A. M. H., Rodriguez-Navarro, A. B., Vidal, M. L., Gautron, J., Garcia-Ruiz, J. M., \&Nys, Y. "Changes in eggshell mechanical properties, crystallographic texture and in matrix proteins induced by moult in hens", British Poultry Science,(2005),pp 46, 268-279. 
[6] S. Nedomova, J. Trnka, P. Dvorakova, "Hen`s eggshell strength under impact loadind", Mendel university agriculture and foresty, Department of food technology, (2009) 350-357

[7] De Ketelaere, B. Govaerts, T. Couke, P.Dewil, E. Visseher, T. Decuypere, "Measuring the eggshell strength of 6 different strains of laying hens: Techniques and comparison", British Poultry Science, (2002). 43, 238-244.

[8] Voisey, P. W., \& Hunt, J. R.. "Effect of compression speed on the behaviour of eggshells". Journal of Agricultural Engineering Research,(1969), 14, 40-46.

[9] Buchar, J. Simeonovova, "On the identification of the eggshell elastic properties under quasistatic compression", In: Proceeding of $19^{\text {th }}$ CAD- FEM users meetig, Berlin, Germany, (2001).

[10] Jacob, J. P. Milles, R. D.\& Mather, F. B...'Egg quality", University of Florida extension, Institute of food and agricultural science,(2000), p. 11.

[11] Narushin, V.G., van Kepmen, T. A., Wineland, M. T., \& Christensen, " Comparing infrared spectroscopy and egg size measurements for predicting eggshell quality", Biosystem Engineering, (2004).

[12] Ebubekir Altuntas, Ahmet Sekerog, "Effect of egg shape index on mechanical properties of chicken eggs", CANADIAN Received 28 May 2007; received in revised form 22 August
2007; accepted 30 August 2007 Available online 24 October 2007.

[13] Anderson, K. E., Tharrington, J. B., Curtis, P. A., \& Jones, F. T., "Shell characteristics of eggs from historic strains of single comb white leghorn chickens and relationship of egg shape to shell strength. International", Journal of Poultry Science, (2004),3, 17-19.

[14] Zlatica, P., Vitorovic, D., Lukic, M., \& Spasojevic, I. "Improving egg shell quality by replacement of pulverised limestone by granular limestone in the hen diet",ActaVeterinaria (Beograd),(2003), 53, 35-40.

[15] Polat, R., Tarhan, S., C, etin, M., \& Atay, U.,"Mechanical behavior under compression loading and some physical parameters of Japanese quail (Coturnixcoturnix japonica) eggs”, Czech Journal of Animal Science,(2007),52, 50-56.

[16] Tung, M. A., Staley, L. M., Richards, J. F., "Estimation Of Young`s Modulus And Failurs Stresses In The Hen`s Egg Shell”, Canadian Agriculcture Engineering, Vol. 11, No. 1, MAY 1969.

[17] Reissner, E., "Stresses and Small Displacements of Shallow Spherical Shells", II. J. Math, 1947.

[18] M.M. Bain, "Eggshell strength: a mechanical/ultrastrucutral evaluation" Ph. D. Thesis, University of Glasgow, Scotland( 1992). 